\title{
Metal Powder and Wire Additive Manufacturing Technology
}

\author{
LIU Yan ${ }^{1, *}$, Du Anna ${ }^{2}$, ZHOU Guishen², LIU Jiapeng ${ }^{2}$ \\ ${ }^{1}$ The Liaoning Provincial Key Laboratory of Advanced Materials \& Prepar ation Technology, Shenyang University, Shenyang 110044 , \\ China; ${ }^{2}$ School of Mechanical Engineering, Shenyang University, Shenyang 110044, China
}

\begin{abstract}
Additive manufacturing techno logy can quick ly manufacture par ts with dense microstructures and excellent mechanical properties, so that it shows a broad application prospect in aerospace and other fields. Additive manufacturing tec hnology w as briefly in troduced in th is paper. On th is basis, the technology and ch aracteristics of $m$ etal powder and wire add itive manufacturing wer e systemati cally analyzed and compared, and the development of additive manufacturing technology was prospected.
\end{abstract}

\section{Introduction}

Additive manufacturing also known as $3 \mathrm{D}$ p rinting, is a technology that combines subjects suc $\mathrm{h}$ as materials science and computer aided design. Through the control of the $\mathrm{s}$ oftware and the numerical $\mathrm{c}$ ontrol system, $\mathrm{t}$ he corresponding ra w mate rials are melted, sintered, a nd light-cured ac cording t o t he three-dimensional m odel, and physicalo bjects are p roduced 1 ayer by 1 ayer. Compared with the past machining method s of cutting and assemb ling raw materi als, it is a manufacturing method in wh ich materials are sup erimposed from bottom to $\mathrm{t} \mathrm{op}^{[1,2]}$. Th is makes it po ssible to mak e complex structural parts that were pre viously restricted by trad itional production methods and were difficult to achieve ${ }^{[3,4]}$. With th e rap id development of the manufacturing $i$ ndustry $i \mathrm{n}$ the $21^{\text {st }}$ cent ury a nd $t$ he proposal of "M ade in $\mathrm{Ch}$ ina 2025", ad ditive manufacturing technology has received wide attention. It has mad e great $\mathrm{p}$ rogress in military man ufacturing, medical i ndustry, automobile $\mathrm{m}$ anufacturing, construction industry, aeros pace, food indust ry, s mall jewelry manufacturing and other aspects ${ }^{[5]}$.
This article outlines the classification of additive manufacturing, and expou nds the research status of metal powder and wire additive manufacturing technology. In addition, the characteristics and applications of metal powder and wire additive manufacturing technolo gy are compared and analyzed.

This has certain theoretical and practical value for the realization of new materials and new technologies in the rapid manu facturing of $\mathrm{p}$ arts and in telligent manufacturing in the future.

\section{Classification of additive manufacturing}

Additive manufacturing started from the end of the 90th century to the middle of the 20th century. It can be said that th e fo cus of add itive tech nology is lay ered manufacturing. The cl assification of co mmonly used additive manufacturing is shown in Table 1[6, 7].

Table 1 Additive manufacturing classification

\begin{tabular}{|c|c|c|c|}
\hline Number & $\begin{array}{l}\text { According to } \\
\text { materials' form }\end{array}$ & $\begin{array}{l}\text { According to heat } \\
\text { source }\end{array}$ & $\begin{array}{l}\text { According to the type } \\
\text { of materials }\end{array}$ \\
\hline 1 & $\begin{array}{l}\text { Wire additive } \\
\text { manufacturing }\end{array}$ & $\begin{array}{l}\text { Wire and arc } \\
\text { additive } \\
\text { manufacturing }\end{array}$ & $\begin{array}{l}\text { Metal materials } \\
\text { additive } \\
\text { manufacturing }\end{array}$ \\
\hline 2 & $\begin{array}{l}\text { Strip/Sheet } \\
\text { additive } \\
\text { manufacturing }\end{array}$ & $\begin{array}{l}\text { Laser additive } \\
\text { manufacturing }\end{array}$ & $\begin{array}{c}\text { Organic polymer } \\
\text { materials additive } \\
\text { manufacturing }\end{array}$ \\
\hline 3 & $\begin{array}{l}\text { Powder materials } \\
\text { additive } \\
\text { manufacturing }\end{array}$ & $\begin{array}{l}\text { Light curing } \\
\text { additive } \\
\text { manufacturing }\end{array}$ & $\begin{array}{l}\text { Biomaterials additive } \\
\text { manufacturing }\end{array}$ \\
\hline
\end{tabular}

$\longdiv { \text { liuyanneu@163.com } }$ 


\section{4

\author{
Liquid materials \\ additive \\ manufacturing
}

\section{Electron beam additive manufacturing}
Inorganic non-metallic materials additive manufacturing

\section{Thermal melting additive \\ manufacturing}

The strip add itive manufactu ring techno logy is mainly used for the forming of lar ge $p$ arts an $d$ the welding $r$ epair wo rk of surfacing welding. How ever, there are few app lications in ad ditive forming $\mathrm{p}$ arts, especially $3 \mathrm{D}$ prin ting, and th ere are relatively few response supp orting equ ipment. At present, metal powder an d wire a re the main research d irections of additive manufacturing.

\section{Metal powder additive manufacturing technology}

Metal powd er add itive manufacturing mainly cov ers electron beam $p$ owder add itive manu facturing, laser powder add itive man ufacturing, an d plasma powd er additive manufacturing.

According to th $\mathrm{e}$ mode of powder feed ing, $t$ he powder add itive manu facturing tech nology is mai nly divided i nto t wo t ypes: powder s preading an $\mathrm{d} p$ owder feeding. In the technology of powd er spreading additive manufacturing, a layer of powder is laid on the table, and the co rresponding heat sou rce is co ntrolled by the computer to selectively sintering the powder according to the predetermined path. Sintered ground is convenient to form the solid part of the parts, and finally the e xcess part can be remov ed fro $m$ th e material to ob tain th $\mathrm{e}$ forming parts. A representative technique of this form is selective laser meltin $\mathrm{g}$ (SLM ) [8,9]. SLM sch ematic diagram is shown in Figure 1. It uses the heat of the laser beam to melt th e metal powd er, th en it fo rms p arts through $\mathrm{c}$ ooling an $\mathrm{d} s$ olidification $\mathrm{p}$ rocess. It has $\mathrm{t}$ he characteristics of no binder, high forming precision and good mechanical properties. However, SL M technology is also limited by so me conditions, such as high requirements for material $g$ ranularity, so it is $d$ ifficult to make. It's n ot suitable for large parts and the re pair of failed parts.

In th e techno logy of powd er feeding add itive manufacturing, h eat sou rce an d pow der feeding nozzle are put together to make the powder directly sprayed into the mo lten pool. The typical tech nique in th is form is laser melting deposition (LM D) [10]. LM D techn ology does not require moulds and can be used to produce parts with co mplex shapes. However, the high forming speed will reduce t he size accurac $y$. LMD has low production efficiency, but relatively high cost.

From the ab ove analysis, it can be seen that metal powder add itive manu facturing tech nology is mai nly related to the quality requ irements of the powder itself and the way of powder spreading or distribution, as well as the external heat sour ce. Gen erally speaking, th e forming quality of metal powd er additive is high, which is especially suitable for $t$ he production of precision small parts. Ho wever, it $h$ as higher requ irements on the equipment an $\mathrm{d}$ e nvironment of $\mathrm{p}$ owder $\mathrm{m}$ anufacturing. The cost of powder manufacturing is higher than that of silk, but the efficiency is lower.

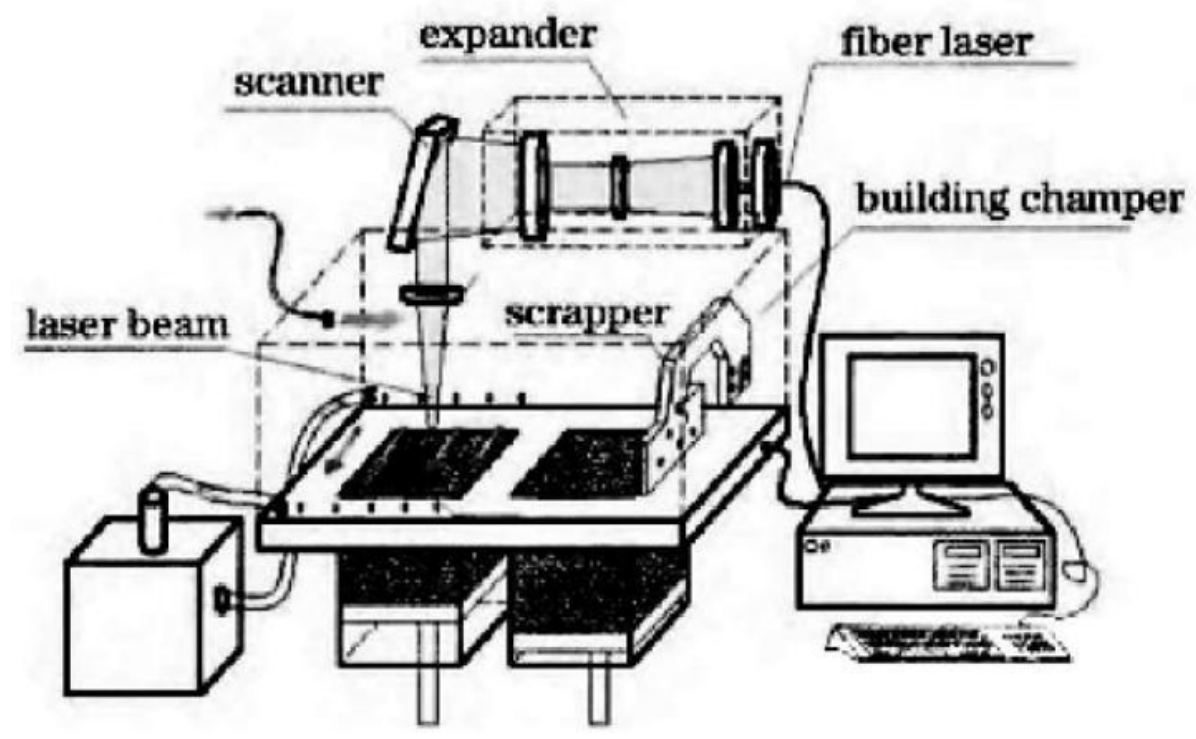

Fig.1 Diagram of SLM technology 


\section{Metal Wire additive manufacturing technology}

In add itive man ufacturing of metal wire, the metal wire is easy to mak e and ch eap. In particular, th e add itive manufacturing technology with wire as electrode has obvious advantages in wel ding speed. It does not need additional wire feed ing equipment, so it can save sp ace and increase efficiency.

\subsection{Laser fuse additive manufacturing technology}

Laser fuse additive manufacturing technology is to melt and accumulate the wire fe $d$ into the laser beam throug $h$ the laser heat to form the required parts. It is often called laser cold wire add itive man ufacturing tech nology. The diameter of the laser fuse is small and the appearance of parts is good.

\subsection{Non-consumable electrode metal wire additive manufacturing technology}

The non-consumable electro de metal wire add itive manufacturing tech nology is a $\mathrm{k}$ ind o $\mathrm{fad}$ ditive technology which usest he corre sponding plasma, electrode beam and tungsten electrode arc as heat source to melt the wire being sent in and then form it. Tungsten inert gas wel ding (TIG) ad ditive manu facturing is a typical metal ad ditive manufacturing tech nology in which wire $\mathrm{i} s$ not use $\mathrm{d}$ as el ectrode. It has $\mathrm{t}$ he characteristics of good fo rming qu ality and fo rming efficiency [1 1]. It is a kind of ad ditive man ufacturing technology th at $\mathrm{p}$ eople are ex ploring gradually, or will become the mainstream in the future.

\subsection{Consuming electrode metal wire additive manufacturing technology}

The con suming electrode metal wire add itive manufacturing tech nology is main ly th e meth od of melting a nd stacking met al wi re b y using t he a rc generated between the wire and the workpiece as the heat source. Cold metal transition weld ing (C MT) additive manufacturing technology has wi dely used in recent years. Generally this kind of additive technology has fast forming sp eed and high production eff iciency, but the surface is rough. CMT has the characteristics of low heat input and no sp lash, which has attracted wi de atten tion [12].

\section{Conclusion and Prospect}

Through th e sy stematic an alysis of metal $p$ owder an $d$ metal wire ad ditive man ufacturing tech nology, it is concluded that metal powder additive manufacturing has high co st and go od forming quality, bu to w forming efficiency. The add itive manufacturing tech nology of fused el ectrode met al wi re has high forming e fficiency and low co st. Its app earance forming quality is wo rse than that of powder ad ditive. It needs to be processed again. Th e fo rmability and manufacturing co st of additive man ufacturing techn ology of non-fused metal wire are between the above two.

Additive manu facturing tech nology is a mu ltidisciplinary tech nology with many influ encing factors. Therefore, it is no $t$ limited to study one subject, but to increase th e cro ss-integration research of add itive manufacturing researchers in multiple subjects and fields At present, there is still a lack of a comp lete set of standards for ad ditive manufacturing techno logy and its quality ev aluation. Th e relevant departments sho uld speed up th e formu lation o f techn ical an d quality standards for additive manufacturing industry.

\section{Acknowledgments}

This work was financially supported by the Program for Liaoning In novative Talen ts in Un iversity (No. LR2019042) and the Liaoning Province Natural Science Fund Project (No. 2019-ZD-0545).

\section{References}

1. Cheng JY, Chang TR. Res earch a nd a pplication status and the trend of metal additive manufacturing technology[J]. China Plan t Eng ineering, 2018(20): 181-183.

2. Ding D, Pan Z, Mominic C, et al. Wire-fee d additive manu facturing of metal components:technologies, d evelopments and fu ture interests[J]. The In ternational Jo urnal of Advanced Manufacturing Technology, 2015, 81(1-4): 465-481.

3. Zhang Y.R esearch on ad ditive manu facturing technology of metal $\mathrm{h}$ igh performance in av iation field[J]. Industrial Heating, 2019, 48(3): 78-80, 84.

4. Li CT. Ap plication of $3 \mathrm{D}$ prin ting technology on thin-walled aeron autic alumin um alloy $\mathrm{p}$ arts[J]. Mechanical and Electrical Information, 2019, (15): 80-81.

5. Liu Y, Ren XH, Chang YL, et al. Research status of metal add itive man ufacturing tech nology[J]. Hot Working Technology, 2018, 47(19): 15-19, 24.

6. Wang D, Lu J, Tang S, et al.Red ucing porosity and refining grains fo $r$ arc add itive manu facturing aluminum al loy by a djusting a rc pulse frequency and current[J]. Materials, 2018, 11(8): 1-14.

7. Yang YH. A nalysis of cl assifications a nd characteristic of additive manufacturing(3D print $)[\mathrm{J}]$. Advances in Aeronautical Science and Engineering, 2019, 10(3): 309-318.

8. Bartkowiak K, Ullrich S, Frick T, et al. New development of 1 aser processing al uminum al loys via ad ditive manufacturing techn ique[J]. Phy sics Procedia, 2011, 12: 393-401.

9. Li YL, Gu DD. Parametric an alysis of th ermal behavior during selectiv e laser melting add tive 
manufacturing of al uminum al loy powder[J]. Materials and Design, 2014, 63: 856-867.

10. Hong $\mathrm{C}, \mathrm{Gu} \mathrm{D}$, Dai $\mathrm{D}$, et al. Laser metal depositon of TIC/In conel 718 comp osites with tailo red interfacial microst ructures[J]. Optics \& Laser Technology, 2013, 54(32): 98-109.

11. Bai JY, Fa n CL, Ya ng YC. Mi crostructures of 2219-Al thin walled parts produced by shaped metal deposion[J]. Transactions of $\mathrm{t}$ he $\mathrm{C}$ hina Wel ding Institution, 2016, 37(6): 124-128.

12. Chen YY, Xu H, Wei QF. Brief discussion on sheet CMT weld ing technology[J]. Au tomobile Parts, 2013(9): 76-77. 